\title{
Genre-Based Inquiry of Literature Review in Social Sciences Master's
}

\section{Theses}

\author{
Gideon S. Sumayo, MALT \\ University of Southern Mindanao-Graduate School, Kabacan, Cotabato, Philippines \\ gsumayo19@gmail.com
}

Donnie M. Tulud, Ph.D.

University of Southern Mindanao-Graduate School and Department of English Language and

Literature, Kabacan, Cotabato, Philippines

dmtulud@usm.edu.ph

DOI: $\underline{\text { http://doi.org/ 10.36892/ijlls.v3i2.584 }}$

\begin{tabular}{|c|c|}
\hline $\begin{array}{l}\text { Received: } \\
\text { 08/05/2021 }\end{array}$ & $\begin{array}{l}\text { Abstract } \\
\text { Literature review (LR) as a distinct type of genre was disregarded continuously, }\end{array}$ \\
\hline $\begin{array}{l}\text { Accepted: } \\
\text { 01/06/2021 }\end{array}$ & $\begin{array}{l}\text { and its rhetorical moves and steps were less explored. Hence, this research } \\
\text { attempted to study the rhetorical structure through move analysis of the LR } \\
\text { section of social science master's theses. The research determined the common } \\
\text { rhetorical moves employed in the } 30 \mathrm{LR} \text { sections of quantitative theses at the }\end{array}$ \\
\hline $\begin{array}{l}\text { Keywords: } \\
\text { rhetorical moves, } \\
\text { genre analysis, } \\
\text { literature review, MA } \\
\text { theses, Philippines }\end{array}$ & $\begin{array}{l}\text { University of Southern Mindanao Graduate School. The rhetorical structure in } \\
\text { the LR sections was examined using the move structure model formulated by } \\
\text { Hsiao and Yu (2012). Results revealed that the thirty LR corpora employed } \\
\text { presenting field knowledge, occupying the niche, but deficient in classifying } \\
\text { themes, and integrating and relating previous works to the current study as their } \\
\text { text features. Findings also revealed that every thesis writer in the } 30 \text { LR } \\
\text { corpora have various ways of presenting their LRs, which means that there is } \\
\text { no general pattern or format in writing LR in thesis manuscripts analyzed. This } \\
\text { implies that the LRs in the master's theses analyzed are written in a variety of } \\
\text { styles depending on the orientation of the writers not following Hsiao and Yu's } \\
\text { prescribed model. Also, an additional step was subsumed under Move } 4 \text { and is } \\
\text { labeled announcing the conceptual framework, which is not evident in the } \\
\text { previously published model structure for LR, which means this step is } \\
\text { considered a new structure in the literature review section evident only in the } \\
\text { USM Graduate School. }\end{array}$ \\
\hline
\end{tabular}

\section{INTRODUCTION}

In every research work, writing the literature reviews section is extremely important. However, it is commonly observed that carrying out the process makes many researchers be theoretically and practically confused, bored, and disorganized. It is undeniably evident, especially to those inexperienced and short-time researchers and graduate students in particular. Hence, the process of writing literature reviews is a difficult task, considered problematic, and painstaking work among novice writers and some researchers (Galvan \& Galvan, 2017).

There are many underlying problems faced by research writers in terms of literature review writing. Mohammed and Ahmed (2019) posit that literature review writing is a time and energy-consuming task which gives a research writer the agony of writing it as it is sternly guided by certain ethics. Commonly, writers find difficulty in understanding and writing a 
literature review, which mainly roots from thinking of what ideas need to be included and how they organize the flow of related concepts and studies. This was supported by Murray and More (2006), who contended that factors such as a feeling of procrastination while initially doing the work, being fixed or choked-up at some point while writing, nervousness and shyness before other writers, and inferiority are some of the reasons why research writers do not like literature review writing.

Similarly, Robbins, Judge, and Vohra (2011) argued that writers of literature reviews often get out-of-focus on the subjects they write about, making them fabricate the works of others because they lack the skills of proper literature review writing. With this, writing literature reviews demands a set of skills such as skills of searching and retrieving literature, unfolding one's ability in analyzing and synthesizing data, and becoming proficient and efficient in writing and reporting even in a limited time frame.

In academic discourse communities, academic writing plays an integral role primarily in terms of communication. With this, it allows written outputs of academic discourse to be acceptable and analyzed from different lenses. Writing in an educational setting like research articles is regarded as a separate genre. In 1994, Thomas and Hawes posited that a research article is determined by "a recognizable communicative purpose and by the presence of characteristic features with standardized form, function, and presentation that are part of its general conventions" (p.131). Writing academic research papers efficiently and successfully should not only be based on grammatical competence but also on comprehending the rhetorical structures such as moves and steps presented in writing academic outputs, which are acknowledged by the discourse community.

Move, which is a functional term, is technically defined as a unit that is regarded as vital in doing genre analysis. Researchers like Lores (2004), Nwogu (1997), Santos (1996), and Swales and Feak (2000) contributed to defining the term. Having said that, move analyses were progressively conducted, anchoring it to the study of Swales in 1990. Many successful researchers dedicated themselves to study other genres in research. Bhatia (1993), together with Lau (2003), Lores (2004), and Santos (1996), attempted to study genres of research abstracts. Kwan (2006) and Hsiao and $\mathrm{Yu}$ (2012) pioneered to study of the genres of writing literature reviews. Genres on research methods were explored by Nwogu (1997), Lim (2006), and Tulud (2017). Hopkins and Dudley-Evans (1988) focused their study on the genres of the results section. Conclusion sections were studied by Bunton (2005), Resurreccion (2018), and Yang and Allison (2003). Hopkins and Dudley-Evans (1988) examined the discussion sections of research articles. Bunton (2005) and Hyland (2004) explored conclusions and acknowledgment sections, respectively.

In the study of Abdullah (2018), it was revealed that move-sensitivity must be implanted and developed earlier to help students write a compelling and informative literature review section. On this note, it is deemed necessary that research writers should be equipped with knowledge about formulating literature reviews using proper moves and steps. Similarly, Jian (2010) stated in his study that surveying and summarizing previous research is one of the essential move structures that may allow learners and novice writers to cope with the structuring problems they usually experience in literature review writing. It can be noted that a researcher should be aware of the appropriate move to address issues regarding literature review writing.

A method that is utilized to investigate the connection of a specific type of text and its observable context through breaking down the text into its simplest semantic units is termed genre analysis. This is considered an important part a researcher should look into. Several studies have been conducted on genre analysis emphasizing literature review sections focusing on doctoral dissertations but dearth on MA graduate theses. It was in 2017 that the study on moves present on the methods section of research in research articles by Tulud was conducted. Thus, research on the move structure focusing on literature review is not yet well explored. In 
the University of Southern Mindanao, there is no study conducted yet exploring the move structures of writing literature reviews specifically under the social sciences field, where most of its offered programs are under this discipline. This dearth in the discipline motivated the researchers to reveal the rhetorical structure of LRs so as to provide descriptions through genrebased inquiry on how LRs in graduate school thesis manuscripts are put into shape and form. Further, there is no information yet about whether the MA writers of the University follow Hsiao and Yu's model or other models in writing literature reviews; hence, the study was deemed indispensable.

In this study, knowing that there are only minimal studies that relate to the analysis of the literature review section, an attempt was made to look into how the moves work in specific genre exemplified in the USM graduate school master's theses and how the writers of different social sciences programs follow particular moves and steps. With the assumption that writers may just write what they think should be the first, thus this study was conducted to provide a rhetorical structure out from their unpublished manuscripts so thesis writers and thesis instructors will know their institutional pattern in presenting their literature reviews.

To examine the rhetorical move structures of literature reviews in MA theses written by MA thesis writers of the University of Southern Mindanao, this study raised the research question:

1. What is the rhetorical structure in the literature review of the social sciences master's thesis at the University of Southern Mindanao Graduate School?

\section{Theoretical Framework}

This study was conceptualized through Hsiao and Yu's (2012) rhetorical moves and steps model for literature review comprising of four moves. The detailed system of order for Literature Reviews is consist of four identified moves: (Move 1) conceptualizing themes in a field, with four steps namely: Step 1: Presenting field knowledge/theory/belief/practices related to the current study, Step 2: Identifying subfields in the major field, Step 3: Organizing major theme(s) to be reviewed for the current study, and Step 4: Surveying research activities; (Move 2) integrating previous works on the themes, with two steps namely: Step 1: Grouping and drawing ideas from source materials to gain a new perspective and Step 2: Critiquing the quality of the research discussed; (Move 3) Relating the previous works to current study, with two steps namely: Step 1: Claiming the relevancy to the current study and Step 2: Indicating a gap; and (Move 4) Advancing to one's own research, with three steps namely: Step 1: Announcing the aim of the research, Step 2: Announcing the research design or the research process, and Step 3: Announcing the theoretical position or the theoretical framework.

\section{METHOD}

\subsection{Data Analyses}

Utilizing the rhetorical move model of Hsiao and $\mathrm{Yu}$ (2012), the researchers analyzed 30 unpublished master's theses of MA writers of the University of Southern Mindanao Graduate School. The master's thesis literature review (hereafter MTLR) section served as the genre and corpora of the study.

The master's thesis literature review was examined and labeled for easy identification and interpretation in terms of their rhetorical structure. The sentences and paragraphs were examined if they indicate expressions such as words or phrases similar to the indicators presented by scholars and previous researchers more particularly in Hsiao and Yu's (2012) move structure for the literature review section.

To analyze the corpus, every statement was coded and classified corresponding to the rhetorical moves of literature reviews established by Hsiao and $\mathrm{Yu}$. To ensure utmost 
confidentiality of the thesis writers, every thesis manuscript was coded MTLR1 to MTRL30 (Master's Thesis Literature Review) instead of revealing their identity.

Also, to further substantiate the analysis, the researchers combined Swales' (2004) and Kanoksilapatham's $(2005,2011)$ criteria classifying moves and steps into three categories: obligatory $(\mathrm{x}=100 \%)$, conventional $(60 \% \leq \mathrm{x}<100 \%)$, optional $(\mathrm{x}<60 \%)$.

\subsection{Data Sources}

There were two primary materials utilized in this study. The first material used was the 30 literature review sections of the master's theses of various social sciences programs such as MA in Language Teaching, MA in Education, MA in Teaching Industrial Arts, MA in Home Economics, and MA in Public Administration.

To analyze the data, the second material used was the four-move model of Hsiao and $\mathrm{Yu}$ (2012) for the literature review section. This model served as the lifeblood of our rhetorical move structure analysis.

\section{FINDINGS AND DISCUSSION}

\section{Introductory Texts}

This study found out that MA thesis writers commonly introduce to the readers the themes, structures, purposes, and justifications for the themes to be reviewed in the following sections, unlike with other literature reviews where utilization of this is not necessary or compulsory. The majority of these introductory texts are relatively short than what we see from the thematic sections in the chapters, which spans between several lines to multiple pages. The finding of this study was in adherence to the analysis of Nguyen (2014) when she revealed that TESOL M.A. theses include introductory texts which span a few line longs. She further explained that the differences in incorporating introductory texts are due to the differently assumed requirements in MA theses or Ph.D. dissertations writing. However, in the study of Hsiao and $\mathrm{Yu}$ (2012), the absence of introductory texts was evident. It can be assumed that the absence of introductory texts in some of the LRs analyzed is partly because of the established academic conventions the thesis writers needed to follow, which is according to Mur-Duenas (2007) this situation is expected since the nature of master's theses varies in terms of the format. Additionally, this unique appearance occurred in 17 out of 30 LRs analyzed. The following examples below are extracted from the corpora to show how writers introduced their LR chapters:

This chapter discusses the review of related literature taken from different studies for easy access to the readers. (MTRL4)

This chapter presents various related literature in the project of a multifunctional board eraser. (MTRL23)

This chapter presents the review of related foreign as well as local literature and studies to the problem being investigated. It also presents and describes the theoretical and conceptual framework of the research study, as well as the hypothesis. From reliable research materials like online research journals and research papers, it provides some facts and relevant theories from authors, international organizations, and notable people to give a clear justification of this study. (MTRL26)

Move 1: Conceptualizing themes in a field

In the analysis, we categorized the first move on the LR sections as Move 1Conceptualizing themes in a field. This move serves as an avenue for the writers to introduce 
built concepts, identify patterns, or categorize themes in the articles reviewed. It accentuates the value and relevance of employed themes for the discussion in the LR sections. This movebased shows that they solitary tend to give knowledge description about the themes as they want to establish the territory. Writers here provide definitions of the terms and even its historical background to put the readers in the context where the writers want to achieve centrality in which they need to carve in the research space. In this move, minimal occurrence for classification was observed since the writers are too focused only on providing description rather than classifying it. Moreover, the function of this move can be realized by the four following steps: (1) presenting field knowledge/theory/belief/practices related to the current study, (2) identifying subfields in the major field, (3) organizing major theme(s) to be reviewed for the current study, and (4) surveying research activities.

\section{Step 1.1: Presenting field knowledge/theory/belief/practices related to the current study}

This step was evident in the corpora since all the researchers utilized this as a component of their LR section in conceptualizing the themes in the field, thus considered as an obligatory move. The writers tend to provide descriptions of the themes they are reviewing. It was also observed that writers are more on giving descriptions rather than classifying the themes. As Hsiao and Yu (2012) and Jian (2010) reported, the realization of this step is attributed to the fact that writers delved much into presenting field knowledge alone than utilizing other moves to present their LRs. Kwan (2006) even highlighted that writers indulged themselves in defining key terms, introducing theories and models, and even highlighting different practices in the field. With this, the step was considered an obligatory move since all of the thesis writers utilized the step.

The following excerpts were drawn from the LR sections to show how these writers present step 1.1:

According to Renaud and Biljon (2008), the user starts having knowledge about the technology and ends up embracing and making full use of it, and hence, the technology is adopted - a process called technology adoption. (MTLR19)

In addition, self-efficacy is defined as believing in one's ability to successfully perform, organize, and perform a task. Motivation has two types namely intrinsic and extrinsic which affect our performances. It served also as our driving force in doing things. Both motivation and selfefficacy are important in order for a certain person to do things well and face misfortunes in a good way (Ersanli, 2008). (MTLR4)

Career exploration is simply learning about various occupations and their fit with unique career preferences, e.g. the skills, interests, and values wanted to satisfy by career. Ideally, it engaged in career exploration during or after identifying your career preferences through self-assessment (Hellman, 2014). (MTRL14)

\section{Step 1.2: Identifying subfields in the major field}

This step was only evident in one LR section understudy; thus, it was considered as an optional move since it only occurred once. This step is the division of the major field into subfields, which requires the researcher's ability and aptitude to make the classification. Hsiao and $\mathrm{Yu}$ (2012) and Hsiao (2015) claimed that this step is necessary since it serves the function of classification, and helps readers trace the organization of ideas and sources. 
The excerpt below was drawn from the LR section to show how the writer illustrated the subfields in the major field of the study:

Self-efficacy was developed by Albert Bandura as part of a larger theory, Social Learning Theory, which advanced into Social Cognitive Theory (Levin, Culkin, and Perrotto, 2001). One's belief that achieving is motivating (Van der Bijl \& Shortridge-Baggett, 2002). Self-efficacy refers to people's judgments about their ability to perform tasks. More simply, self-efficacy is what an individual believes he can accomplish using his skills under certain circumstances (Snyder \& Lopez, 2007). (MTRL4)

\section{Step 1.3: Organizing major themes to be reviewed for the current study}

This step is evident in all the LR sections understudy. This can be identified easily since these are just sub-headings for the past literature the writer will incorporate in his/her study. The step was considered a conventional move since 29 (96.67\%) out of 30 thesis writers used this in presenting their LRs. The findings conform to the studies of Hsiao and $\mathrm{Yu}$ (2012) and Jian (2010) since most of their analyzed corpora have demonstrated the classification of key themes. They further implicated that this step happens because it bolsters readers to know the classification of topics in the LR section. The following excerpted sub-headings or major themes were drawn from the LR sections to show how these writers organized major themes to be reviewed for the current study:

\section{Meaning of Dynamic Written Corrective Feedback (MTRL6)}

\section{Republic Act 10121: The Philippine Disaster Risk Reduction and Management Act of 2010 (MTRL7)}

\section{Eating Habits and Health Consciousness (MTRL16)}

\section{Step 1.4: Surveying research activities}

In this step, it presents the research activity components-aims, participants, methods, results, and conclusions. According to Hsiao and $\mathrm{Yu}$ (2012), this step is expected to be lengthy since it discusses the complete reports about a study. The study substantiates the findings of Kwan (2006); Hsiao \& Yu (2012); Nguyen (2014); and Abdullah (2018) on their research with literature review sections of MA theses which revealed that the usage of this step is prevalent among literature sections as it helps writers be critical in their stance, and it allows readers to be familiar and conscious with the presented knowledge. The step was considered a conventional move since $26(86.67 \%)$ out of 30 thesis writers used this. This step is illustrated in the following examples below:

Alemi (2010) investigated the role of using word games in expanding the learner's vocabulary. In so doing, she used five-word games, named (Twenty Questions. Charades, Definition Game's, Passwords, and Crossword Puzzles). She selected the participants randomly from a male/female group of third grade junior high school students and also randomly divided them into two groups: experimental and control. Control group were taught words using traditional methods, however, the experimental group received word games as a treatment at the end of each session. Finally, a vocabulary test was administered to both groups to determine the differences between them. The score confirms the positive effect of word games on expanding learner's vocabulary. (MTRL1) 
In a study on the impact of teachers' qualification on students' performance, Colfalter, Ladd, and Vidgor (2006) found that there is no significant difference exists in the mean performance of students in schools staffed with qualified teachers and those staffed with unqualified teachers. (MTRL15)

The main purpose of Motiwalla's study was to create an archive of consolidated and secured records of student information, assessment results, and attendance stored in Android-based mobile phones. By utilizing mobile devices, the recording, searching, viewing and updating of the students' academic information will be faster and handy, and thus, the deliberation of a framework for "m-learning" (mobile phone-based learning,) a subset of e-learning, by the researcher as a way of supplementing traditional classroom-based teaching. As stated by the researcher, using mobile phones in teaching and classroom management is great assistance, particularly to an educator and generally to the academic institution. (MTRL19)

\section{Move 2: Integrating previous works on the themes}

In this step, after giving knowledge description and themes classification, integration of previous works to support or disproving the themes is utilized. This move is realized through the following consequent steps: (1) grouping and drawing ideas from various source materials to gain a new perspective and (2) critiquing the quality of the research discussed.

\section{Step 2.1: Grouping and drawing ideas from source materials to gain a new perspective}

This step was found to be evident in several LR sections. It was considered as an optional move since $13(43.33 \%)$ out of 30 thesis writers employed this. More so, this step presents the summary of various previous works that were brought together to support a theme. The findings conform to the study of Hsiao and Yu (2012), in which they stated that writers have minimal utilization of the step, and limited sections of the literature reviews are devoted to the integration of past studies. Also, it corroborates the findings of Hsiao (2015) which she revealed that the MA theses she analyzed had shown the occurrence of this step but with minimal occurrence, too, particularly in low-rated literature reviews. Moreover, Nguyen's (2014) study reported that she even found the same results and stated that this happens when a lack of familiarity with the moves and steps occurs. This step is illustrated in the following examples below:

Thus, in order to attain flawlessness, one could experience sequences or continuous drill for it hints to automaticity. DeKeyser's principles of skills acquisition and skill-development model only gives further provision for Evan's theory of corrective feedback, which was established with two main goals; improve the advantage and reduce the affliction (Evans et al., 2010; Hartshorn et al., 2010; and Mehrnoosh, Manijah \& Daryoush, 2013). Corrective feedback has four main beliefs as polished by Evans, asserting that this method should be significant, well-timed, unceasing, and convenient (Evans et al., 2010 \& 2012; Hartshorn et al., 2010). (MTRL 6)

Whereas, the strong predictor of employees' attitudes as the type of work were country and culture as cited in the studies of Saari (2000); Erez (2002); Schneider (2001). (MTRL8) 
Morale is an essential factor that adds to the people's readiness to work, leads to happiness, and defines the organization's success. If people have high morale, they are enthusiastically willing to work towards the attainment of organizational goals and lead them to put more importance to group goals than their personal interests. On the other hand, low morale will put employees to inefficiency, low productivity, waste, and indiscipline to employees. Morale refers to the employees' attitude, emotional and mental state towards the task he is likely to... (Senge, 1990; Seroka, 2009; and Haddock, 2010). (MTRL11)

\section{Step 2.2: Critiquing the quality of the research discussed}

This step is utilized once in the LR section; hence, it was considered as an optional move. The weaknesses, strengths, and limitations, and/or a misdirected concept underlying the research and/or unresolved conflicts among the research writers of previous studies concerning a research topic are presented in this step. It can be observed that MA thesis writers at the University of Southern Mindanao Graduate School were deficient in the field of critiquing previous works, which adhere to the findings of Hsiao and Yu (2012) when they revealed that there is seldom evidence of critiquing. But this is very understandable since the research writers are a novice in the field of literature reviewing and follow no specific framework in undertaking it; thus, the absence of particular steps is likely expected. The following example shows how the step is demonstrated:

Rolin-Ianziti and Brownie opposed those studies about the intralingual teaching strategy. They emphasized that the first language of students is valuable in order to come up with the right interpretation of the new input of the English language. A similar study with Macaro, he mentioned that most students are expecting L1 teaching instruction from their teachers to check comprehension. Some of the students said that it is complicated on their side to understand their teachers in English teaching instruction. Macaro came up with the result through surveys, interviews, and also classroom observation, in order to investigate the first language and target language use among teachers. His study revealed that teachers really use L1 in many ways: to give directions for students' tasks, to give remarks for the output of students, and to scrutinize students' understanding. (MTRL2)

\section{Move 3: Relating previous works to the current study}

After synthesizing and evaluating previous studies, establishing a relationship between the synthesis/evaluation and the proposed study is called for at this very stage. The following two steps (1) claiming relevancy to the current study and (2) indicating a gap are the essential features that will help achieve the function of this move.

\section{Step 3.1: Claiming relevancy to the current study}

In this step, the MA thesis writers offer affirmative assertions of previously conducted studies. Usually, this is presented through a brief centrality claim as well as giving a brief explanation of the key themes reviewed, then followed up by giving the relevancy of the current study (Kwan, 2006). In this way, it helps in answering the question of why the proposed study should be conducted. This move does not appear in all of the MA theses; hence, it is considered a non-evident move.

\section{Step 3.2: Indicating a gap}


In the corpora of the study, the researchers only observed the utilization of Step 2Indicating a gap among $8(26.67 \%)$ out of 30 thesis writers. Though there is a minimal occurrence, Kwan (2006) confirmed that this step leads the researcher to put the readers in the context to evaluate the need for conducting the research. Hsiao and $\mathrm{Yu}$ (2012) also pointed out that after synthesizing and critiquing, this step will move forward to establish a relationship between integration and the proposed study. They also pointed out that many of the research writers show their relevancy through gap indication than relevancy claiming. This notion conforms to the understudy since there was no step involving the claiming relevancy to the current study.

This step can easily be identified since it presents a variable or factor in previous works that were overlooked. This will give the researcher the reason why to conduct his/her study since its purpose is to fill the gap. Additionally, according to Sandberg and Alvesson (2010), establishing the gap is a scholarly step that would lead to a new and interesting topic to explore in research.

The following examples below illustrated this step:

Critics of multi-sector collaborations have argued that there remains a lack of strong evidence showing the direct impact of the multi-sectoral approach to development and implementation that results in social and community benefit (Foster-Fishman, Berkowitz, et al., 2001; Himmelman, 2001; and Kaye, 2001). The complex labor requirements of an in-depth study of multisectoral collaboration (MSC) effectiveness have been identified as a factor contributing to this lack of a research-based framework (Foster-Fishman, Berkowitz, et al., 2001). (MTRL9)

In the 1980's, the focus of second language acquisition focused more on syntax and morphological features rather than the acquisition of vocabulary (Read, 2013). The small scope of research had yet to discover the processes associated with second language learning and the impact vocabulary learning had on second language acquisition. Meara (2002), a leading researcher in second language acquisition, noticed this lack in research and began extensive work in language vocabulary acquisition research in 1980. (MTRL3)

Past research has consistently supported the importance of self-efficacy in the career exploration process (Rogers et al., 2008). However, self-efficacy is not limited to career exploration and planning. An individual's sense of self-efficacy also influences his or her career performance, persistence (Betz, 2004) and interests (Gushue et al., 2006). Given this finding, selfefficacy is a key variable in many aspects of the career selection, decisionmaking, and performance processes. (MTRL14)

\section{Move 4: Advancing to one's own research}

From the data collected, it revealed that this move is utilized more than in the analyzed theses in the study of Hsiao and $\mathrm{Yu}$ (2012). It was stated in their study that this move was not frequently used in the LR sections to advance to their own researches. Hsiao and Yu (2012) suggested that this move is equally important as it unravels the niche being created in the previous three moves. Thus, this move becomes the platform to occupy the niche as what this step can do and realize. Jian (2010) also pointed out that this step is distributed somewhat evenly without a clear preference for any given strategy or 'step' as we termed it in the study. The findings of this study contradicted this notion because, in the analyzed corpora, all steps 
were presented and utilized. Additionally, this step is common in the analyzed corpora. The findings also revealed similar to what Nguyen (2014) exposed when she analyzed the MA theses written by Vietnamese writers. Correspondingly, this move is considered essential since it is the final means for occupying the niche and a way to transcend to the methodological section of a certain study. Move 4 can be realized by the four following steps (1) announcing the aim of the research, (2) announcing the research design or the research process, (3) announcing the theoretical position or theoretical framework, and (4) announcing the conceptual framework.

\section{Step 4.1: Announcing the aim of the research}

In this step, it carries statements announcing the targets of investigation by the aims of the investigation, research questions to answer, and hypotheses to test. The step was considered a conventional move since $23(76.67 \%)$ out of 30 thesis writers used this. According to Hsiao and $\mathrm{Yu}$ (2012) and Hsiao (2015), this step is utilized to make the aim of the proposed study known. Jian (2010) even pointed out that the inclusion of this step is to direct LR discourse towards Move 4 to make topic development.

This can be easily recognized since each step that was undertaken is highlighted in the form of headings. The following examples are shown below to illustrate the step:

\section{Hypothesis}

Henceforth, the main objective of this study is to identify the perceived factors influencing job performances between Seedgarden employees. In furtherance, the null hypothesis was created:

Hol: The socio-economic profile of the respondents does not have a significant relationship with the job performance of employees.

Ho2: The determinants such as salary, stress, work environment, and workload do not significantly influence the job performance of the employees. (MTRL8)

\section{Hypothesis}

Hol: There is no statistically significant difference in scores on vocabulary acquisition between the control group and the experimental group. (MTRL3)

\section{Hypothesis}

In this study, the following hypotheses were formulated:

1. There is no significant relationship between the TLE teacher's classroom management and practices.

2. There is no significant relationship between classroom management of TLE teachers and their students' achievement.

3. There is a significant relationship between the TLE teachers' practices and their students' achievement. (MTRL15)

\section{Step 4.2: Announcing the research design or the research process}

In this step, it is an introduction to denote a description of the research methodology. It is usually accompanied by figures to show the process graphically. It even presents the output of the study. This step is only evident in the LR sections of the Master of Arts in Teaching Industrial Arts (MATIA). As Jian (2010) states, the inclusion of this step may be credited to the purpose of reaching the final move, which is to indicate a niche. It can be gleaned from the result that this step is optional since it was only utilized by $6(20.00 \%)$ out of 30 thesis writers in the corpora. The following examples are shown below to illustrate the step: 
The conceptualization of the project started with the input, which includes the concepts taken from the books, internet, and other references related to the study, which leads to designing with the availability of materials, supplies, tools, and equipment. The throughput includes planning, designing, constructing, testing, and revising its operation. Then, the output of the study is a complete solar powered aerator for aquatics.

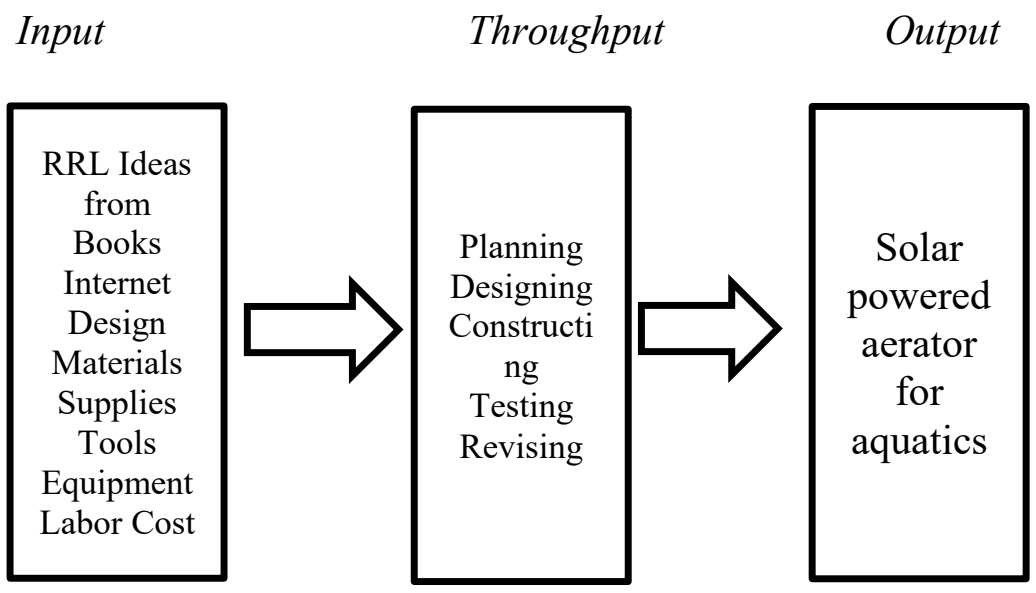

Fig. 1. Project Development Procedure (MTRL21)

\section{Step 4.3: Announcing the theoretical position or the theoretical framework}

This step is presented to denote the synthesized theoretical framework from the incorporated literature works. And also, it offers the readers the knowledge on where will be the understudy be anchored upon. More so, this step is illustrated in the last thematic unit of the LR chapter. Aside from that, this step is also seen as not evident in the LR sections of the Master of Arts in Teaching Industrial Arts (MATIA). The step was considered an optional move since $12(40.00 \%)$ out of 30 thesis writers employed this. Theory announcement is indispensable since it is generally used to occupy the niche (Hsiao \& Yu, 2012). Moreover, in the corpora understudy, theoretical frameworks are easily identified since each step that was undertaken is highlighted in the form of headings.

\section{Theoretical Framework}

This study was anchored on the constructivist viewpoint which believes that students can learn better by themselves through experience and exploration of authentic contexts and discovering new things from their own experiences. (MTRL3)

\section{Theoretical Framework}

The study is anchored from Abraham Maslow's Motivation Theory. It is a motivation that functions to drive, energize, and sustain behavior. The behavior of an individual is being energized to arouse it for function. It is also prolonged behavior in the course of activity. In Maslow's hierarchy of needs, the physiological needs must be met first. (MTRL26)

\section{Theoretical Framework}


This study was anchored on Vygotsky's Cognitive Development Theory that features interaction as it plays an important part in molding the mental aspect of a student (Dahms et al., 2007). (MTRL13)

\section{Step 4.4: Announcing the conceptual framework}

The researchers categorized this as a different step since, in the corpora of the study, this step is written separately from the theoretical framework. This move is considered a conventional move since $76.67 \%$ or 23 research writers used the step. Also, this step is utilized to present the dependent and independent variables of the study graphically and textually. In addition, the research writers also write this after the theoretical framework is presented. So, it occurs next when a theoretical framework is present. But in the corpora, some did not employ a theoretical framework; instead, they directly presented the conceptual framework depending upon the appropriateness. Moreover, this structure move is not evident in Hsiao and Yu's (2012) and Kwan's (2006) model structures for LR, which means this step is considered as a new structure in the LR section.

Below are examples that best demonstrate the step:

\section{Conceptual Framework}

\begin{tabular}{|c|c|c|}
\hline $\begin{array}{l}\text { Input } \\
\text {-Pre-test } \\
\text { (paragrap } \\
\text { h writing } \\
\text { which will } \\
\text { be } \\
\text { evaluated } \\
\text { through a } \\
\text { rubric) }\end{array}$ & $\begin{array}{l}\text { Process } \\
\text { - Daily } \\
\text { writing } \\
\text { activities } \\
\text { which will } \\
\text { be } \\
\text { evaluated } \\
\text { through a } \\
\text { rubric }\end{array}$ & $\begin{array}{l}\quad \text { Input } \\
\text { Post-test } \\
\text { (paragraph } \\
\text { writing } \\
\text { which will } \\
\text { be } \\
\text { evaluated } \\
\text { through a } \\
\text { rubric) }\end{array}$ \\
\hline
\end{tabular}

Figure 1. Conceptual Framework of the study showing the essential elements in the conduct of dynamic written corrective feedback to the student-respondents. (MTRL6)

\section{Conceptual Framework}

The conceptual framework of the study, as shown in Figure 1 below, portrays the relationship between self-efficacy and language proficiency of the respondents. The independent variable considered in this study is selfefficacy and its domains, namely academic, social, and emotional. The dependent variable is the respondents' language proficiency in terms of speaking, writing, and reading. (MTRL4)

Conceptual Framework 


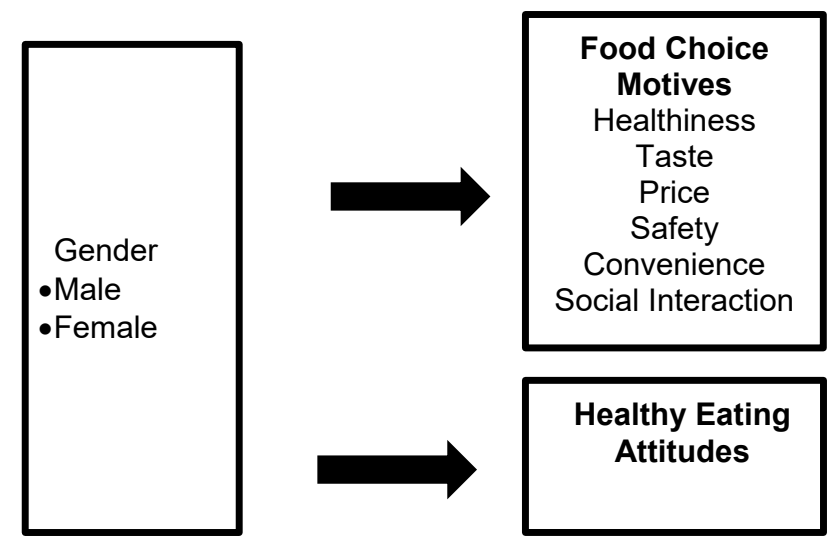

Figure 1. Schematic design, which identifies the variables of the study. (MTRL16)

Table 1 Occurrences of Rhetorical Moves and Steps in Literature Review

\begin{tabular}{|c|c|c|}
\hline Rhetorical Moves and Steps & $\begin{array}{l}\text { Frequency } \\
\mathbf{N}=\mathbf{3 0}\end{array}$ & $\begin{array}{l}\text { Percentag } \\
\text { e }\end{array}$ \\
\hline Introduction & 17 & $56.67 \%$ \\
\hline \multicolumn{3}{|l|}{ Move 1: Conceptualizing themes in a field } \\
\hline \multicolumn{3}{|l|}{ Step 1: Presenting field knowledge/theory/belief/practices related } \\
\hline to the current study & 30 & $100 \%$ \\
\hline Step 2: Identifying subfields in the major field & 1 & $13.33 \%$ \\
\hline $\begin{array}{l}\text { Step 3: Organizing major theme(s) to be reviewed for the } \\
\text { current study }\end{array}$ & 29 & $96.67 \%$ \\
\hline Step 4: Surveying research activities & 26 & $86.67 \%$ \\
\hline \multicolumn{3}{|l|}{ Move 2: Integrating previous works on the themes } \\
\hline $\begin{array}{l}\text { Step 1: Grouping and drawing ideas from source materials to } \\
\text { gain a new perspective }\end{array}$ & 13 & $43.33 \%$ \\
\hline Step 2: Critiquing the quality of the research discussed & 1 & $10 \%$ \\
\hline \multicolumn{3}{|l|}{ Move 3: Relating previous works to the current study } \\
\hline Step 1: Claiming relevancy to the current study & 0 & $0 \%$ \\
\hline Step 2: Indicating a gap & 8 & $26.67 \%$ \\
\hline \multicolumn{3}{|l|}{ Move 4: Advancing to one's own research } \\
\hline Step 1: Announcing the aim of the research & 23 & $76.67 \%$ \\
\hline Step 2: Announcing the research design or the research process & 6 & $20.00 \%$ \\
\hline $\begin{array}{l}\text { Step 3: Announcing the theoretical position or the theoretical } \\
\text { framework }\end{array}$ & 12 & $40.00 \%$ \\
\hline Step 4: Announcing the conceptual framework & 23 & $76.67 \%$ \\
\hline
\end{tabular}

Note: $\quad 0 \%$ - non-evident move

$<60 \%$ - optional move

$>60 \%$ - conventional move

$100 \%$ - obligatory move

\section{CONCLUSION}

The current research unveiled the rhetorical structure in the literature review of the social sciences master's theses at the University of Southern Mindanao Graduate school. It was revealed that MA thesis writers have distinctive ways of presenting their literature review sections, although the Graduate School of the University of Southern Mindanao has established conventions in terms of writing the literature review. It can be observed that some of the MA thesis writers' LRs do not reflect the rhetorical move structure prescribed by Hsiao and Yu (2012), and even of those such as Jian (2010), Hsiao (2015) in literature reviews. Hence, some moves and steps were considered to be optional and conventional. Most of the MA thesis 
writers utilized Move 1, specifically Step 1.1, 1.3, and 1.4, in presenting their LRs. There was a deficient utilization in terms of presenting the LR using Move 2 and Move 3, particularly Step 2.1, 2.2, and 3.1, 3.2, respectively. On the other hand, several thesis writers successfully occupied the niche since most of their LRs employed Move 4, particularly Step 4.1, 4.2, 4.3, and 4.4. The findings also revealed that before presenting their LRs, introductory texts are incorporated.

The results then imply that MA thesis writers in USM Graduate School devoted so much to presenting field knowledge, but not much to integrating previous studies and relating the current study to the previous works, which according to Hsiao and $\mathrm{Yu}$ (2012), is a major flaw. They emphasized that this happens when writers are not consciously aware of the full role of the LR in a thesis.

Also, based on the analysis, one new step was found unique, and one step proposed by Hsiao and $\mathrm{Yu}$ (2012) has not occurred. With this at hand, the way the thesis writers presented their LR in graduate school led the researchers to propose a new model for masters' theses under the field of social sciences, which are quantitative. To accord, the absence of some steps in the corpora is the result of the different nature of masters' theses since disciplines vary in terms of their characteristics or format (Mur-Dueñas, 2007; Nguyen, 2014). It can be gleaned from the result that some offered programs under social sciences field might have different characteristics or format in their research papers since each program have different requirements in presenting their LR. One notable finding is the absence of theoretical framework or conceptual framework in the LR sections of Master of Arts in Teaching Industrial Arts since their studies are more on patent or invention and do not require anymore any framework to follow. Hence, it can also be concluded that some steps frequently used by the writers amidst diversity in disciplines would reveal that these specific steps can be considered characteristics or format of their LR sections.

The results from the analysis of the comparable corpus indicate that there is a minute difference in the extent of inclusion of some steps in the LR sections in the five courses under the social sciences field; however, the presentation of the moves and steps varies. This entails that there is no universal pattern in presenting the LRs in MA theses. Findings also revealed that writers employed similar rhetorical moves and steps in their LR chapters, which can be safe to say that they are shaped and not constrained in dealing with the rhetorical structure of the LR. Though there is no fixed order in terms of the moves distribution, yet its appearance in the corpora would tell that writers manifested the understanding on how they should present their LR despite differences in the discipline.

\subsection{Implications for Educational Practice}

The theoretical contributions of this research to discourse analysis propose practical implications to those interested in pedagogy, particularly in academic writing. Since in the corpora, the move structure of literature review section in social sciences master's theses was outlined, and some weaknesses were identified from the move utilization in students' literature reviews, the research stresses to implicate two things: introduce the move structure of literature review to students' level of understanding, and plan courses to solve the weaknesses identified in this study.

The common move structure found in this study should be explicitly taught in thesis writing classes to produce impactful theses, particularly the LR section. This is manifested in the studies of Kwan (2006) and Hsiao and Yu (2012) when they found in their research findings and established common rhetorical patterns in literature reviewing. If and when students are aware of the conventions of literature reviewing, such as move structure and its linguistic realizations, it can empower them to become adept academic readers and writers.

The current study showed that most of the MA thesis writers use more of a description of past studies than classification to conceptualize themes for readers since the nature of the 
MA theses was more on affirming, testing or validating existing theories and not on conceptualizing or developing a theory or principle. Therefore, if there will be a change in the nature of the MA theses, instructors should perhaps design "classification tasks" to help learners become acquainted with discovering and exploring similar and/or different features on given topics that might be coming from source articles such as books, theses, dissertations, technical reports, and assign proper themes to the features found. Hence, it is deemed necessary to employ task-based language teaching as it helps in attaining the aims of the designed curriculum, with great consideration on the level, need, and interest of the students (Bhandari, 2020). Also, the MA research writers showed less of integrating and relating previous works to the current study; therefore, research instructors may hold training or workshops that would let the students criticize research papers in terms of methodological inappropriateness or theoretical/conceptual mishaps. With this, students will be able to sharpen their minds and even their writing skills, helpful in developing their critical insights. These are not easy tasks since it requires readers to read vast information from research papers, and must tacitly make classifications based on certain points, integrate studies from summarized source articles, and related studies through understanding research's relevance. More so, to achieve this proficiency, guidance also from the instructors is indispensable.

\subsection{Implications for Future Research}

Concerning the implications for future research, the researchers propose that further research be undertaken to focus on another discipline to find out if discrepancy still occurs or if there are unique characteristics on how the LR is tailored in that particular discipline.

Additionally, research may explore using the same corpora utilizing other move structures and come up with a writing guide to help novice writers write the LR section correctly. Correspondingly, it may further examine move combinations and configurations in various sections extant in the literature review to give a clear picture of LR writing and help research instructors to provide effective and efficient pedagogical instruction appropriate to the student's needs.

\section{REFERENCES}

Abdullah, F. (2018). Moves within the literature reviews and discussion sections of international postgraduate theses and dissertation on ELT and applied linguistics. EEAL Journal (English Education and Applied Linguistics Journal), 1(2), 174-183. https://journal.institutpendidikan.ac.id/index.php/eeal/article/view/373/3

Bhandari, L. P. (2020). Teaching writing through task-based instruction: Exploring English teachers' experiences. International Journal of Language and Literary Studies, 2(4), 177-186. https://doi.org/10.36892/ijlls.v2i4.466

Bhatia, V. K. (1993). Analyzing genre: language use in professional settings. Longman.

Bunton, D. (2005). The structure of PhD conclusion chapters. Journal of English for Academic Purposes. 4. 207-224. 10.1016/j.jeap.2005.03.004.

Galvan, J. L., \& Galvan, M. C. (2017). Writing literature reviews: A guide for students of the social and behavioral sciences. Routledge.

Hopkins, A., \& Dudley-Evans, T. (1988). A genre-based investigation of the discussion section in articles and dissertations. English for Specific Purposes, 7, 113-122. 
Hsiao, C., \& Yu, H. (2012). Knowledge Presentation in Thesis Writing-Examining Move Use in Reviewing Literature. English Teaching and Learning, 36 (3), 1-47.

Hsiao, Cheng-Hua. (2015). Genre Analysis of Low-rated and High-rated Literature Reviews by EFL Postgraduates. International Journal of English Language Teaching. 3. 10.5430/ijelt.v3n1p1.

Hyland, K. (2004). Disciplinary discourses: Social interactions in academic writing. Longman.

Hyland, K. (2004). Graduates' gratitude: the generic structure of dissertation acknowledgements. English for Specific Purposes, 23, 303-324.

Jian, H. (2010). The schematic structure of literature review in research articles of applied linguistics. Chinese Journal of Applied Linguistics, 33 (5). http://www.celea.org.cn/teic/93/11030302.pdf

Kanoksilapatham, B. (2005). Rhetorical structure of biochemistry research articles. English for Specific Purposes, 24(3), 269-292.

Kanoksilapatham, B. (2011). Civil engineering research article Introductions: Textual structure and linguistic characterization. The Asian ESP Journal, 7(2), 55-84.

Kwan, B. (2006). The Schematic structure of literature reviews in doctoral theses of applied linguistics. English for Specific Purposes, 25(1), 30-55.

Lau, H. (2003). The structure of academic journal abstracts written by Taiwanese PhD students. Taiwan Journal of TESOL, National Chengchi University.

Lim, J. M. H. (2006). Method sections of management research articles: A pedagogically motivated qualitative study. English for Specific Purposes, 25 (2006) 282-309.

Lores, R. (2004). On RA abstracts: from rhetorical structure to thematic organization. TESOL Quarterly, 23, 280-302.

Mohammed, I.S., \& Ahmed, M. (2019). Problems of academic literature review and writing: The way forward. 16. 11-26.

Mur-Dueñas, P. (2007). 'I/we focus on ...': A cross-cultural analysis of self-mentions in business management research articles. Journal of English for Academic Purposes 6(2). $143-162$.

Murray, R., \& S. Moore. 2006. The handbook of research writing: A fresh approach. McGraw Hill and Open University Press.

Nguyen, T. (2014). A move-based structure of the master's thesis literature review chapters by Vietnamese TESOL postgraduates. LangLit: An International Peer-Reviewed Open access Journal. 1. 282-301.

Nwogu, K. (1997). The medical research paper: structure and functions. English for Specific Purposes, 16(2), 119-138. 
Resurreccion, M. (2018). Genre analysis of conclusions sections of quantitative dissertations among graduate schools in Davao city. University of Mindanao, Davao City.

Robbins, S. P., Judge, T. A., \& Vohra, N. (2011). Organisational behaviour. Pearson Education.

Sandberg, J., \& Alvesson, M. (2010). Ways of constructing research questions: Gap-spotting or problematization? Organization. 18. 10.1177/1350508410372151.

Santos, M. (1996). The textual organization of research paper abstracts in applied linguistics. Text, 16, 481-499.

Swales, J. M. (1990). Genre Analysis: English in Academic and Research Settings. Cambridge University Press.

Swales, J. M. (2004). Research Genres: Exploration and applications. Cambridge University Press.

Swales, J. M., \& Feak C. B. (2000). English in today's research world: A writing guide. University of Michigan Press.

Thomas, S., \& Hawes, T. P. (1994). Reporting Verbs in Medical Journal Articles. English for Specific Purposes, 13, 129-148.

Tulud, D. (2017). Probes on the rhetorical moves of research methods in research articles. ASIAN EFL Journal. 98, 16-26.

Yang, R., \& Allison, D. (2003). Research articles in applied linguistics: Moving from results to conclusions. English for Specific Purposes, 22(4), 365-385.

\section{AUTHORS' BIO}

Gideon S. Sumayo is a faculty at the Senior High School Department, School of Basic Education, Southern Christian College, Midsayap, Cotabato, Philippines. He is a graduate of Master of Arts in Language Teaching major in English from the University of Southern Mindanao, Kabacan, Cotabato, Philippines. He is pursuing Doctor of Philosophy in Education major in Applied Linguistics, at the University of the Immaculate Conception, Davao City, Philippines. He teaches English-related subjects in the Senior High and Junior High levels specializing in Reading and Writing Skills and English for Academic and Professional Purposes.

Donnie M. Tulud is a faculty at the Department of English Language and Literature, College of Arts and Social Sciences, University of Southern Mindanao (USM) - Kabacan, Cotabato. He finished his Doctor of Philosophy in Applied Linguistics at the University of the Immaculate Conception, Davao City, in 2015. He is currently an Associate Professor 4 and the Program Head of Master of Arts in Language Teaching Major in English in the same university. 